\title{
Service Quality and Its Effects on Customer's Satisfaction: A Case Yirgalem Town Telecommunication, Ethiopia
}

\author{
Tesfaye Nigussie \\ Injibara University: College of Business and Economics, Yirgalem, Ethiopia
}

\begin{abstract}
The main objective of this study was to investigate the effects of service quality on the customer satisfaction at Yirgalem telecom service industry. To conduct this study, a descriptive survey was employed. Questionnaire survey, document analysis and review of journals were used to collect necessary data. The research study involved one category of sample populations: obtained by conveniently available respondents were Customers/subscribers of the Yirgalem telecom industry. Data analysis was done using descriptive statistical tools and percentage. Again inferential statistics which includes both regression and correlation were employed to show the strength of relationships between independent variables (service quality dimensions) and dependant variable (customer satisfaction). The study findings indicate that there are positive and significant relationships between five service quality dimensions and customer's satisfaction. And also there is positive and strong effects were recorded among three service quality variables (empathy, responsiveness and reliability) than assurance and tangibility. Finally, there is a positive relationship between service quality and customer satisfaction. This study concludes that these factors should be fulfilled or improved at the organizational level to satisfy customers through improving the quality of services. The researcher strongly recommends that there needs to be, acquiring reliable network, good customer handling and having clear and accurate bill, attract new skilled manpower from the market and finally the management should have to works towards the improvements over all service quality dimensions.
\end{abstract}

Keywords: Customers Satisfaction, Service Quality, Servqual Model.

DOI: $10.7176 /$ JIEA/9-2-02

Publication date: April $30^{\text {th }} 2019$

\section{Introduction}

Nowadays, with the increased competition, service quality has become a popular area of academic research and has been acknowledged as an observant competitive advantage and supporting satisfying relationships with customers as Zeithmal, (2000) stated.

The survival of any business organization depends on the satisfaction of its stakeholders or customers. Customers were the major and critical ones among those stakeholders. They are the sources of profit for profit making organization and the primary reason for being in operation for any non- profit making organization. Thus customers are considered as the back bone of any organization (Robert-Phelps, 2003). With regard to the impact of service quality dimensions on customer satisfaction, many researchers are come up with different conclusion about the impact of service quality dimensions on customer satisfaction. For instance, Mengi (2009), indicated that responsiveness and assurance are more significant. Whereas, empathy had the highest positive correlation with customer satisfaction followed by assurance and tangibility. On the other hand, Arasliet.al, (2005), found that reliability had the highest impact on customer satisfaction. Finally, a number of studies have identified the dimensions of service quality as the antecedents of customer satisfaction (Lau et al., 2013, Saghier, \& Nathan, 2013).

In the contemporary environment where business is expanding and competition is stiff both nationally and internationally; doing business becomes a great challenge. Therefore, in order to overcome this challenge organizations (businesses) are developing different strategies to achieve their long run objective and for survival. One of the best strategies is about satisfying the customer that ensures a long term growth and profitability of business. As a result, the importance of customer satisfaction for the existence of an organization is obvious or clear.

In telecom sector the number of subscribers and value added services are increasing from time to time, but the users are not satisfied with the quality and availability of the service. For instance from the year 2003/04 to 2007/08 the number of subscriber increased nearly by five folds compared to the early year of its introduction (ETC Statistical Bulletin, 2008/2009) and service equality of the country is poor and its coverage is limited in comparison to other African countries.

\subsection{Statement of the problem}

The introduction of telecommunication services in Ethiopia dates back to 1884, seventeen years after the invention of telephone technology in the world. It a state owned enterprise and the sole telecom service provider in the country. The telecommunication services in Ethiopia have made rapid stride both in quality and quantity. However, the user at large are found dissatisfied with quality and quantity of the services made available to them. The process 
of technological sophistication has gained the momentum but the users are yet to get the quality and quantity of service (Tele Negarit, 2007). ETC provides national and international telecommunications services, using communication media of satellite, optical fiber, microwave, multiple access radius, very small aperture, ultra high frequency and very high frequency. Currently, it provides the following major types of service packages such as landline and wireless fixed, mobile, internet and data services for its government, business, and private and other non-government organizations which are locally and internationally. Similar service packages were provided to the Yirgalem city telecom service industry, since the industry is one of the stake holders of ethio telecom. Therefore, the aim of this research was assessing the effect of service quality from the consumer's perspective through assessing their Expectations and perceptions of service quality.

\subsection{Objectives of the study}

* To inform the company to what extent customers are satisfied by service quality dimensions.

* To state clearly which quality dimensions are more important or significant for customer satisfactions.

* To examine the relationships between service quality and customers satisfaction of Yirgalem telecom industry with regard to service quality dimensions.

\section{Literature review}

In today's constantly changing business environment, providing superior quality through adequate and strong focus on customers is one of key factor for enabling firms to gain lasting competitive advantage in winning the market (chiara, G.2007).

For this, now a day's marketers trying to focus more on continues monitoring and evaluation of service quality, involving various innovative offerings and service developments which have a direct influence on customers service experience (Laghari,2011). From the studies carried out in many countries, factors like service quality and perceived value are the key constructs affecting customer satisfaction with telecommunication. For example, a recent study by Ojo (2010), in the telecommunication industry showed that a positive relationship exists between service quality and customer satisfaction.

In addition to this, Studies dealing with the relationship between satisfaction and a service quality have shown that a higher level of service quality leads to a higher level of customer satisfaction (Pollack, 2008, p. 537). On the other hand, some studies could not show a strong relationship between the service quality and the customer satisfaction (Lovreta et. al., 2010, p. 121) and in relation to the quality of a product, it is more difficult for customers to measure objectively the quality of service, due to the intangibility as one of the main characteristics. Therefore, the authors do not give consent regarding the definition of service quality as quoted from the above scholars by (Velida and Kijevčanin2012).

With regard to the impact of service quality dimensions on customer satisfaction, many researchers are come up with different conclusion about the impact of service quality dimensions on customer satisfaction. For instance, Mengi (2009), indicated that responsiveness and assurance are more significant. Whereas, empathy had the highest positive correlation with customer satisfaction followed by assurance and tangibility. On the other hand, Arasliet.al, (2005), found that reliability had the highest impact on customer satisfaction. Finally, a number of studies have identified the dimensions of service quality as the antecedents of customer satisfaction (Lau et al., 2013, Saghier, \& Nathan, 2013). Service quality is a focused evaluation that reflects the customer's perception of essentials of service such as relations quality, physical environment quality, and outcome quality. According to Yoo and Park (2007), service quality is the firm's ability to create and sustain competitive advantage depends upon the high level of service quality provided by the service provider. Besides, Jayaraman et.al. (2010) define it as the customer's overall impression and cognitive judgment of the relative inferiority or superiority of the organization and its services or as the difference between customer expectations for the service and them perceptions of the service received.

The SERVQUAL model is proved to best advisable instrument to measure customer service and perceived satisfaction. This model includes five dimensions. First, reliability which refers to the company ability to provide services on time. Second, responsiveness which deals with the extent to which service provider's readiness to provide quickly. Third, assurance, this dimension focuses on the ability of workers to communicate trust to customers or their professional ability related to the service. Fourth, empathy, related with care and attention given to the customers. Lastly, tangibility which is related with the observable facilities or it might be personnel and in general it is physical facilities (Loke, etal. 2011).

\section{Research methodology}

\subsection{Research design}

Accordingly, from different types of research designs descriptive type of research design was employed for this paper for the realization of intended objectives to describe the service quality effect to customers. This research design is a fact finding study with adequate and accurate interpretation of findings and furthermore, it allows 
describing both qualitative and quantitative approaches (Kothari, 2004). The researcher would employ the survey method. The questionnaire will be designed related to service quality elements such as empathy, reliability, and responsiveness, assurance, and tangibility effects towards customer's satisfaction among other factors.

\subsection{Sampling design and techniques}

The researcher prefers to use convenience sampling technique to get the required information from the required respondents at a place. But in order to determine sample size or to determine sample respondents, the researcher determine to use Cochran's formula for calculating sample size when the population is infinite. Cochran (1977) developed a formula to calculate a representative sample for infinite populations.

$$
\mathrm{n}_{0}=\frac{\mathrm{z}_{\alpha / 2}^{2} \mathrm{pq}}{\mathrm{d}^{2}}
$$

no $=1.962 * 0.5 * 0.5 / 0.052=385$

Where, no is the sample size, $\mathrm{z}$ is the selected critical value of desired confidence

Level, the value for $\mathrm{Z}$ is found in statistical tables which contain the area under the normal curve $\mathrm{Z}=1.96$ for $95 \%$ level of confidence, $p$ is the estimated proportion of an attribute that is present in the population, which is 0.5 and $\mathrm{q}=1-\mathrm{p}$ and $\mathrm{e}$ is the desired level of precision.

\subsection{The study variables}

Student satisfaction measures related with service quality dimensions (tangibility, assurance, responsiveness, empathy and reliability)

\subsection{Data collection method}

There are two major approaches to gathering information about person, situation, problem or phenomena. Sometimes, information required is already available and only need to be extracted. However, there are times when the information must be collected. Based up on those broad approaches to information gathering, data are categorized as secondary data and primary data. Survey approach is the most common method of primary data collection.

\subsection{Method of data analysis}

Descriptive data analysis would be used to reduce the data into a summary format and also transforming raw data into a form that will make them easy to understand and interpret. The data collected from the questionnaire were summarized using statistical package for social science (SPSS version 20) and Microsoft excel by means of statistical methods such as tabulation, average mean and frequency count, in a way that can show the level of customer satisfaction. In addition to this, to show the degree of relationship among independent variables and dependent variables, inferential data analysis technique were used by the researcher. Inferential data analysis consists of regression and correlation was employed by the researcher to estimate the degree and nature of relationships between variables.

\section{Results and discussion}

Correlation coefficients

Correlation is a statistical method that determines the degree of relationship between two different variables or correlation is a statistical technique that can show whether and how strongly pairs of variables are related. 
Table 4.1. The Correlation Result of Service Quality and customers Satisfaction in yirgalem telecommunication .

\begin{tabular}{|l|c|c|}
\hline Service Quality & Total student Satisfaction \\
\hline \multirow{4}{*}{ Tangibility } & Pearson correlation & $0.493^{* *}$ \\
\cline { 2 - 3 } & Sig.(2-tailed) & 0.000 \\
\cline { 2 - 3 } & $\mathrm{N}=$ & 380 \\
\cline { 2 - 3 } & Pearson correlation & $0.587^{* *}$ \\
\cline { 2 - 3 } & Sig.(2-tailed) & 0.000 \\
\hline Assurance & $\mathrm{N}=$ & 380 \\
\cline { 2 - 3 } & Pearson correlation & $0.555^{* *}$ \\
\cline { 2 - 3 } Responsiveness & Sig.(2-tailed) & 0.000 \\
\cline { 2 - 3 } & $\mathrm{N}=$ & 380 \\
\cline { 2 - 3 } & Pearson correlation & $0.649^{* *}$ \\
\cline { 2 - 3 } & Sig.(2-tailed) & 0.000 \\
\hline Empathy & $\mathrm{N}=$ & 380 \\
\cline { 2 - 3 } & Pearson correlation & $0.845^{* *}$ \\
\cline { 2 - 3 } Customer Satisfaction & Sig.(2-tailed) & 0.000 \\
\cline { 2 - 3 } & $\mathrm{N}=$ & 380 \\
\cline { 2 - 3 } & Pearson correlation & 1 \\
\cline { 2 - 3 } & Sig.(2-tailed) & 380 \\
\hline
\end{tabular}

** Correlation is significant at the 0.01(2-tailed)

Source:- SPSS Correlation Output, 2019

As the above table 4.1 Depicts, The final result of the correlation indicated that all service quality dimensions (tangibility, empathy, reliability, responsiveness and assurance) have positive and significant relationship with the customer's satisfaction. As briefly described on the above table 4.12, the highest and very strong relationship were recorded between empathy $(\mathrm{r}=0.845, \mathrm{p}<0.01)$ and customers satisfaction. This implies that service provider staff gives individual attention for the students, knows what the students actually want, students have interest in the services provided by the service provider, and the service provider operates according to the working hours that are convenient to most of the customers. The next highest score is between responsiveness $(r=0.649, \mathrm{p}<0.01)$ and student satisfaction. This implies the service provider staff tells the student exactly when Services will be performed; customers receive prompt service from the service provider staff, if any interruptions occur, Service provider staff is always willing to help the students, Service provider staff does not appear to be too busy in responding student requests and the complaint resolution or fault repair is fast. Whereas reliability $(\mathrm{r}=0.587$ $\mathrm{p}<0.01)$, assurance $(\mathrm{r}=0.555 \mathrm{p}<0.01)$ and the least and weak relationship is between tangibility $(\mathrm{r}=0.493, \mathrm{p}<0.01)$ and student satisfaction with the slight difference from reliability and assurance. Therefore, this implies that their relationship is moderate to student satisfaction than empathy and responsiveness.

\section{Multiple regressions}

Multiple Regression measures the strength of the influence of the multiple independent variables on a single dependent variable. Regression measures the strength of a relationship between an independent variable and a dependent variable. When comparing two different variables, one questions come to mind: "Is there a relationship between two variables?" this questions is answered by regression.

The independent variable also called the explanatory variable or predictor variable is the x-value in the equation. The independent variable is the one that you use to predict what the other variable is. The dependent variable depends on what independent value you pick. It also responds to the explanatory variable and is sometimes called the response variable. The explanatory variable or predictable variables were tangibility, assurance, responsiveness, empathy and reliability. The only dependent variable was customers satisfaction.

Table 4.2. Regression result of service quality and customers satisfaction

\section{Model summary}

\begin{tabular}{|l|r|r|r|r|}
\hline Model & R & R Square & Adjusted R Square & Std. Error of the Estimate \\
\hline 1 & $.882^{\mathrm{a}}$ & .778 & .775 & 1.78419 \\
\hline
\end{tabular}

a. Predictors: (Constant), assu, relia, res, tan, emp

As the above table 4.13 depicts that, the coefficients of determination $\mathrm{R}^{2}$ are 0.775 . This shows that independent variables of service quality explain 77.5 percent of dependent variable (customers satisfaction). The rest of 22.5 percent is explained by other factors or variables out of the scope of the study. According to (Zenithal and Bitner, 2004) satisfaction is influenced by perception of service quality, product quality, as well as situational 
factors and personal factors. As the above researchers discussed, other factors that determine customer's satisfaction might be product quality, price, personal and situational factors.

Table 4.3. The analysis of variance (ANOVAa)

\begin{tabular}{|rl|r|r|r|r|r|}
\hline Model & Sum of Squares & df & Mean Square & F & Sig. \\
\hline \multirow{2}{*}{1} & Regression & 4166.779 & 5 & 833.356 & 261.786 & $.000^{\mathrm{b}}$ \\
& Residual & 1190.572 & 374 & 3.183 & & \\
& Total & 5357.351 & 379 & & & \\
\hline
\end{tabular}

a. Dependent Variable: cust

b. Predictors: (Constant), assu, relia, res, tan, emp

In the above ANOVA table, the column labeled, sum of squares describes variability in the customer satisfaction value of the regression. The regression sum of the squares is the deference between total sum of the squares and residual sum of the squares which is $(\mathrm{TSS}-\mathrm{RSS}=5357.351-1190.572=4166.779)$. The total degree of freedom is $380-1=379$, one class less than the number of observation. The regression model has sums of the mean square of 833.356(4166.779/5), and residual mean square is 3.183(1190.572/374).

The proposed model was adequate as the $\mathrm{F}$-static $=261.786$ were significant at 1 percent level $(\mathrm{p}<0.01)$. This represents that the model was reasonable fit and there was statistically significant association between service quality dimensions (reliability, responsiveness and empathy) and customer satisfaction.

Table 4.4. Regression Result to customers Satisfaction over Service Quality service quality dimensions of yirgalem telecommunication.

\begin{tabular}{|c|c|c|c|c|c|c|c|c|}
\hline \multirow{2}{*}{\multicolumn{2}{|c|}{ Model }} & \multicolumn{2}{|c|}{$\begin{array}{l}\text { Unstandardized } \\
\text { Coefficients }\end{array}$} & \multirow{2}{*}{$\begin{array}{c}\text { Standardized } \\
\text { Coefficients }\end{array}$} & \multirow[t]{2}{*}{$\mathrm{T}$} & \multirow[t]{2}{*}{ Sig. } & \multicolumn{2}{|c|}{ Co linearity Statistics } \\
\hline & & B & Std. Error & & & & Tolerance & VIF \\
\hline \multirow{6}{*}{1} & (Constant) & .256 & .563 & & .454 & .650 & & \\
\hline & Emp & .664 & .040 & .644 & 16.432 & .000 & .387 & 2.584 \\
\hline & Tan & -.025 & .037 & -.022 & -.671 & .503 & .559 & 1.789 \\
\hline & Res & .104 & .037 & .093 & 2.776 & .006 & .530 & 1.886 \\
\hline & Relia & .328 & .042 & .259 & 7.897 & .000 & .552 & 1.810 \\
\hline & Assu & .084 & .047 & .058 & 1.802 & .072 & .572 & 1.747 \\
\hline
\end{tabular}

A. Dependant variable; Customer satisfaction.

B. Explanatory variables; empathy, tangibility, responsiveness, reliability and assurance.

Source: Computed from SPSS 20, 2019

Therefore, the estimated or dependent variable $\mathrm{Y}$ (customers satisfaction), $\mathrm{Y}=0.256+0.664 \mathrm{x}_{1}+0.328 \mathrm{x}_{2}$ $0.025 \mathrm{x}_{3}+0.104 \mathrm{x}_{4}+0.084 \mathrm{x}_{5}$. This is the regression equation of dependent $(\mathrm{Y})$ and independent variable $(\mathrm{X})$. As the above table shows, to what extent, the service quality dimensions of (empathy, reliability, tangibility, assurance and responsiveness, have more significant effects on customers satisfaction respectively. But, the service quality dimensions of empathy have positive and significant effects on customers satisfaction followed by reliability and responsiveness. But assurance dimension of the service quality have slight positive effects on customers satisfaction and tangibility has no positive and significant effects on the customer's satisfaction.

\subsection{Summary of Findings}

Finally the overall aim of this study was to investigate the effects of service quality on customer's satisfaction in the yirgalem town. The investigation was made on service quality dimensions and customers satisfaction to determine to what extent service quality dimensions exert influence on the customers satisfaction. Therefore, to determine the effects of service quality on customer satisfaction, SERVQUAL model were employed to prepare the questionnaire with 28 items for the respondents.

With regard to correlation result shows that all service quality dimensions (tangibility, empathy, reliability, responsiveness and assurance) have positive and significant relationship with the customer's satisfaction. But the highest and positive correlation were recorded between empathy $(r=0.845, p<0.01)$ and student satisfaction. The next highest score is between responsiveness $(\mathrm{r}=0.649, \mathrm{p}<0.01)$ and customers satisfaction. Whereas reliability $(\mathrm{r}$ $=0.587 \mathrm{p}<0.01)$, assurance $(\mathrm{r}=0.555 \mathrm{p}<0.01)$ and the least and weak relationship is between tangibility $(\mathrm{r}=0.493$, $\mathrm{p}<0.01)$ and customers satisfaction. Therefore, assurance and reliability have moderate relationship to customer's satisfaction than empathy and responsiveness. For instance, Mengi (2009) study indicated that responsiveness and assurance are more significant relationships. Whereas, empathy had the highest positive correlation with customer satisfaction followed by assurance and tangibility. In addition to this, Reliability, tangibility and empathy are more positively related to customer satisfaction (Jamal and Anastasiadou 2009). In this research, there are positive and direct relationships between service quality dimensions and customers satisfaction, but the weak relationship was 
recorded between tangibility and student satisfaction.

The regression model showed that $77.5 \%\left(\mathrm{R}^{2}=0.775\right)$ of the observed variability in total student satisfaction is explained by the total service quality variables. But the rest 22.5 percent shows that dependent variable (customer satisfaction) is explained or determined by other factors out of the scope the study. The findings of the other researchers show that, according to (Zenithal and Bitner, 2004), satisfaction is influenced by perception of service quality, product quality, situational factors and personal factors. As the above researchers discussed, other factors that determine customer's satisfaction might be product quality, personal and situational factors.

\subsection{Conclusion}

The ultimate aim of the research was to assess the effects of the service quality on customer's satisfaction in yirgalem town. The study tried to test the relationship between service quality dimensions and student satisfaction. Besides this, the effects of the service quality dimensions and customers satisfaction were tested through the means of regression and correlation coefficients.

There is a positive relationship between service quality and customers satisfaction. Obtaining customer satisfaction depends to a large extent on ensuring that the firm maintains high service quality standards. Putting in place quality mechanisms has significant effect on the level of student satisfaction. Service quality dimensions specifically tangibility, assurance, reliability, empathy and responsiveness have strong and positive correlation with customers satisfaction.

Finally, there is positive and strong effects were recorded between empathy, responsiveness and reliability dimension of service quality. Therefore, Customer satisfaction is subjective; therefore, it is not appropriate to treat it as a single-stimulus factor, rather, it should be treated as a multi-stimulus factor.

\subsection{Recommendation}

Based on the findings and conclusions the following constructive recommendations were given to the top service quality management and the staff of the university.

Finally, the summary of recommendation forwarded by the researcher were, Telecom management needs to emphasize service quality. Due to the fact that telecom industry does not provide tangible products, their service quality is usually assessed by measures of the service-provider's relationship with customers. Thus, university management should pay attention to staff skill possession, knowledge, attention to students and their needs, offering of fast and efficient services and general attitude to customer services. Other issues for improving upon student satisfaction in the university include fairness among students, trustworthiness, consulting the students, and provision of tutorial class for students. Policymakers for the university should have to see student satisfaction based on these measures. Invariably, there is need for the management of university to intermittently train their workers on relationship skills. Such training would build a customer-oriented climate in which contact staff can deliver service efficiently and effectively, acknowledging that generating competent and knowledgeable students is the very essence of university

\subsection{Implication for future research}

As the present research examined service quality factors in a single firm, additional studies need to be undertaken to examine customer satisfaction patterns in other regions and with larger samples. Nevertheless, the researcher would argue that his findings provide additional insight into customers' perceived satisfaction within the telecommunications domain. Results of this study should encourage strategy development for superior service quality management in the areas of tangibility, reliability assurance, empathy and responsiveness. But there are other factors that cause customers satisfaction out of the discussed factors in the study. The factors might be political, economic, and cultural factors. Therefore, this implication provides the insight to others for further investigation to examine those factors.

\section{Reference}

$>$ Agyapong, G. The effect of service quality on customer satisfaction in utility industry:Acase of vodafon (Ghana).. International Journal of business and management,.

$>$ Anderson,E.W.,Fornell,c.,and Mazyancheryl,S., 2004. Customer Satisfaction and shareholders value.. Journal of marketing, 68 (October),, pp. 172-185.

$>$ Andeson,E.W., and Fornell,C., 1994. A customer satisfaction Research service Quality. new Direction in theory and practice, pp. 241-268.

$>$ Anon., 2020. Global telecommunication study; navigating the road to,. [Online] Availableat:ey.com[Accessed 11 february 2016].

$>$ Anon.,n.d.[Online]Availableare:http://en.wikipedia.org/wiki/Irgalem[Accessed 3 February 2016].

$>$ Boulding, k. v., 1993. A dynamic model of service quality;From expectation to behaviorial intensions.. Journal pof marketing research,, Volume 30(2),, pp. 7-27. 
> Brady,M.K.,and Cronin,J.J., 2001a. Some New thoughts on conceptualizing perceived service quality:A heirarchical approach.. Journal of marketing, Volume Vol.65(3), pp. 34-49.

$>$ Carrillat,F.and Jaramillo,F.M., 2007. The validity of the SERVQUAL and SERVPER Scales;a meta analytic view of 17 years of research across five continents. International Journal of Service Industry Managment ;, Volume 18 No.5, pp. 472-490.

> Caruana,A.Money,A.H., and Berthon,P.R., 2000. Service quality and satisfaction:The modern role of value.. Europian Journal of Marketing ;, Volume 34(11/12), pp. 1338-1353.

$>$ Kothari, 2004. Research Methodology Methods and Techniques,. 2nd ed. ed. New Delhi;: New Age International Publisher..

$>$ Zeithaml, Valarie A., parasurman, A. and Berry,Leonard L., 1990. Delivering quality service; New york,: Free press..

$>$ Zeithaml, V., 2000. Service quality, profitability and economic worth of customers; What we know and what we need to learn.. Journal of marketing science,, Volume 28 No.1, pp. 67-85.

$>$ Zeithaml, V. B. a. G., 2009. Service marketing; Integrating customer focus across the firm.. New york: Mc Graw-Hill.. 